This item was submitted to Loughborough's Research Repository by the author.

Items in Figshare are protected by copyright, with all rights reserved, unless otherwise indicated.

\title{
Evaluation of inertial response controllers for full-rated power converter wind turbine (Type 4)
}

PLEASE CITE THE PUBLISHED VERSION

http://dx.doi.org/10.1109/PESGM.2016.7741837

PUBLISHER

(C) IEEE

VERSION

AM (Accepted Manuscript)

\section{PUBLISHER STATEMENT}

This work is made available according to the conditions of the Creative Commons Attribution-NonCommercialNoDerivatives 4.0 International (CC BY-NC-ND 4.0) licence. Full details of this licence are available at: https://creativecommons.org/licenses/by-nc-nd/4.0/

\section{LICENCE}

CC BY-NC-ND 4.0

\section{REPOSITORY RECORD}

Gonzalez-Longatt, Francisco M., Andrea Bonfiglio, Renato Procopio, and B. Verduci. 2019. "Evaluation of Inertial Response Controllers for Full-rated Power Converter Wind Turbine (type 4)". figshare. https://hdl.handle.net/2134/23662. 


\section{Evaluation of Inertial Response Controllers for Full- Rated Power Converter Wind Turbine (Type 4)}

\author{
Francisco M. Gonzalez-Longatt \\ The Wolfson School: Electronic, Electrical and Systems \\ Engineering, \\ Loughborough University \\ Loughborough, United Kingdom \\ fglongatt@,fglongatt.org
}

\author{
A. Bonfiglio, R. Procopio and B. Verduci \\ Department of Electrical, Electronic, Telecommunications \\ Engineering and Naval Architecture \\ University of Genoa \\ Genoa, Italy
}

\begin{abstract}
One of the main challenges in future power systems is the enormous integration of generation units using high power converters as interface, it decouples new power sources from the AC power grid, incapacitating a natural frequency response. This situation decreases the total system inertia affecting the ability of power system to overcome system frequency's disturbances. This paper evaluates two inertial controller for fullrated power converter wind turbines, Type 4: (A) releasing "hidden" inertia controller and (B) fast power reserve emulation. Simulations over a test system are used for a preliminary evaluation of the mentioned inertial controllers. The main contribution of this paper is to demonstrate the main differences between system frequency response (SFR) obtained by each inertial controller and how important is to match wind turbine and system characteristic to improve the SFR.
\end{abstract}

Index Terms - Frequency controller, frequency stability, power system, protection scheme, wind turbine generator.

\section{INTRODUCTION}

Future energy systems will look completely different to the power systems on nowadays [1], [2]. High and low power converters will be massively deployed almost everywhere into on the electric network [3], [4] and for very different use: (i) high power interfaces of the renewable energy produced by highly variable generators [5], [6], [7], (ii) interface of several technologies for energy storage, each one with very different time constants, and (iii) interconnecting several synchronized power systems, creating an Pan-European transmission network which facilitate the massive integration of large-scale renewable energy sources and the balancing and transportation of electricity markets. The high/low power converters typically tend to decouple energy sources from the preexistent AC power systems [4], [2]. During a system frequency disturbance (SFD) the generation/demand power balance is lost, the system frequency will change at a rate initially determined by the total system inertia $\left(H_{T}\right)$. However, future power systems will increase the installed power capacity (MVA) but the effective system inertial response will stay the same nowadays [8]. The result is deeper frequency excursions of system disturbances.
There are several good papers [1]-[3], [9], and technical reports [10]-[11] dealing with theory [12]-[13], modelling [14] and simulation [15] of inertial response of wind turbine generators (WTG) and some of them provide general ideas about possible impacts on power systems and their effects on transient under-frequency response [16]-[17]. Even some controls strategies have been proposed to mitigate the impact of reduced inertia [18].

This aim of this paper is to evaluate two inertial controller for full converter wind turbine (FCWT) -Type 4: (A) releasing "hidden" inertia controller and (B) fast power reserve emulation. The paper is organized as follows. Section II introduces the frequency control in wind turbines and presents details of inertial response controllers: (A) releasing "hidden" inertia controller and (B) fast power reserve emulation. Section III presents the main description of the system modelling and system frequency response (SRF). Time domain simulation are used to evaluate the SRF provided by the inertial controllers, presented in Section IV. The main contribution of this paper is to highlight the main differences between SFR obtained by each inertial controller and how important is to match wind turbine and system characteristic to improve the SFR. Finally, the advantages/disadvantages of inertial controller are discussed in Section V.

\section{FREQUENCY CONTROL IN WIND TURBINES}

Frequency control in power systems is usually formed of primary and secondary control. Future power system will require an active participation of wind power generation on the primary and secondary frequency control. Although generators electronically controller and/or electronically connected to the grid do not provide FR, this capability can be obtained by adding a supplementary control to the power converters [1]. Several control schemes can be drawn to enable the wind power generation to provide FR, it can be divided into threelevel hierarchy [1]: (i) wind turbine controller -local control, (ii) wind farm controller, (iii) power system level controller. Local control at wind turbine level is used to provide primary frequency control and other additional auxiliary services then wind farm level controller allows coordination between the 
central and local control in order to achieve the desired generation for the system. Power system level controllers are used for secondary frequency control; it provides better system frequency behavior by the coordination between the AGC and the wind farms. Wind turbine level controllers are local controllers added to the VSWT subsystems in order to enable transiently support the frequency. They can enable the primary frequency control by two strategies [19]: (i) inertial controller and (ii) governor controller. In this paper, the main concern is related to the inertia controller, it can be created in several approached, there are two basic approaches: (A) Releasing "Hidden Inertia" and (B) Fast Power Reserve Emulation. Those controllers are described in details in the next subsections.

\section{A. Releasing "Hidden Inertia"}

Modern WTGs use power electronics converters to enable variable speed operation in order to capture wind energy over a wide range of speeds. However, power converter isolates the rotational speed from the system frequency so WTG based on back-to-back AC/DC/AC converters offer no natural response to system frequency [20], [14].

The WT industry has created several controllers for modern WTG's in order to provide inertial response (and governor response on some cases) for large frequency deviation for, short-duration, releasing hidden inertia. There are several names for this sort of controllers: Artificial, Emulated, Simulated, or Synthetic Inertial. Examples of synthetic inertia controlled commercially available for WTG are [21]: General Electric WindINERTIA ${ }^{\mathrm{TM}}$ [22], ENERCON $^{\circledR}$ Inertia Emulation [23].

The objective of the synthetic inertia control is "to extract the stored inertial energy from the moving part on WTGs" [24]. There are several versions of synthetic inertia controllers; however they can be classified in two main approaches: (a) Releasing "hidden" inertia and (b) Reserve capacity in pitch. In this paper the hidden inertia approach is considered and it is named synthetic inertia from here on.

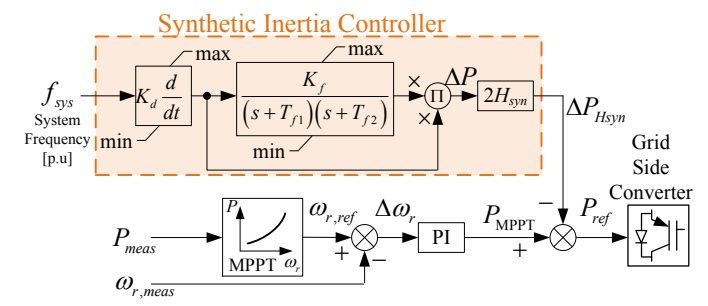

Figure 1. Representative block diagram of Maximum Power Point Tracking (MPPT) controller and Releasing Hidden Inertia (shadowed) [1], [21], [19].

Synthetic inertia concept allows a controller to the take the kinetic energy from a WT rotating mass. This controller is well-explained in several publications [15], [12]. Its control loop increases the electric power output during the initial stages of a significant downward frequency event. The active power (inertial power, $\Delta P$ ) of the control is achieved by:

$$
\Delta P=2 H_{s y n} \cdot f_{s y s} \cdot \frac{d f_{s y s}}{d t}
$$

where $H_{\text {syn }}$ express the synthetic inertia (sec) and $f_{\text {sys }}$ system frequency (p.u). Implementation of synthetic inertia controller is depicted on Figure 1.

\section{B. Fast Power Reserve Emulation}

The fast-power reserve emulation controller is designed to provide a short term constant power, and it can provide frequency response for a short period of time [25], [26], [27]. The fast-power reserve $\left(P_{H s y n}\right)$ is derived from a simple integration of kinetic energy stored in the wind turbine rotor:

$$
P_{H s y n} t=\frac{1}{2} J_{s y n}\left(\omega_{r, 0}^{2}-\omega_{r, \mathrm{f}}^{2}\right)
$$

where $t\left(t<t_{\max }\right)$ is the lasting time of the fast-power reserve since the beginning of the frequency disturbance, $\omega_{r, 0}$ is the initial rotational speed and $\omega_{r, \mathrm{f}}$ is the rotor rotational speed corresponding to $t$.

This controller acts on the reference rotational speed creating an artificial change on the rotational speed to allow release kinetic energy from the wind turbine rotor. The change on the rotational speed $\left(\omega_{r \text {,ref }}\right)$ is obtained as:

$$
\omega_{r, \mathrm{ref}}=\omega_{r, \mathrm{f}}=\sqrt{\omega_{r, 0}^{2}-\frac{2}{J_{s y n}} P_{H s y n} t}
$$

A general scheme for the fast-power reserve emulation controller is depicted on Figure 2. The fast power reserves provides FR for a short period and save time for other slower generators to participate in the frequency control.



Figure 2. Representative block diagram of Maximum Power Point Tracking (MPPT) controller and Fast Power Reserve Emulation (shadowed) [1].

\section{SYSTEM MODELLING}

This section presents system modelling used in this paper. A very simple test system is considered, as shown of Figure 3.

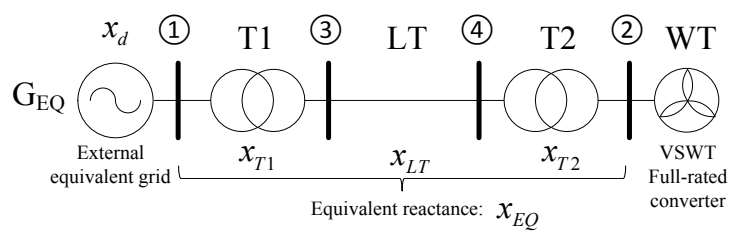

Figure 3. Test system: Representative transmission system including an equivalent wind turbine.

It consists of a large equivalent external grid $\left(\mathrm{G}_{\mathrm{EQ}}\right)$ connected to a wind turbine (WT) using a multi-voltage level transmission system. For simplicity, this is a lossless transmission system and reactances of transformer and transmission system can be combined together (bus (3) and (4) disappear) and an equivalent reactance $\left(x_{E Q}\right)$ used instead. The 
next subsections presents details of the modelling of the different aspects relevant for SFR. The main grid is assumed to be characterized by a total inertia $\left(H_{n e t}\right)$ equal to $40 \mathrm{~s}$ (on machine power base) and a $5 \%$ equivalent droop.

\section{A. Wind Turbine (WT) Model}

Figure 4 depicts the general structure of a variable-speed wind turbine (VSWT) with a direct-drive (DD) permanent magnet synchronous generator (PMSG). This wind turbine uses a full-rated power converter in the form of back-to-back topology. The models used full-rated converter and their details are taken from [2, 19, 21]. Models parameters used are escalated to simulate an equivalent $5 \mathrm{MW}$ wind turbine.

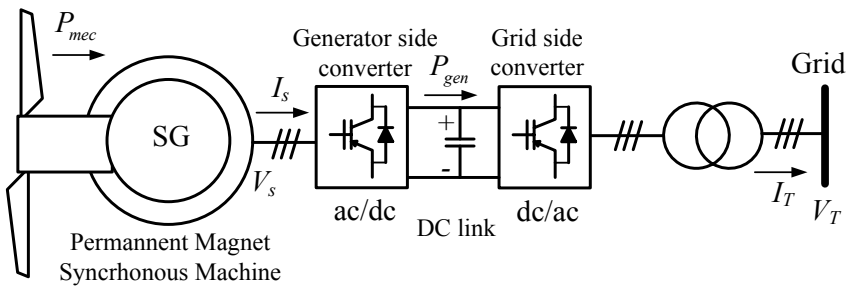

Figure 4. General structure of a variable-speed wind turbine (VSWT) with a direct drive synchronous generator with a full-rated power converter as interface to grid.

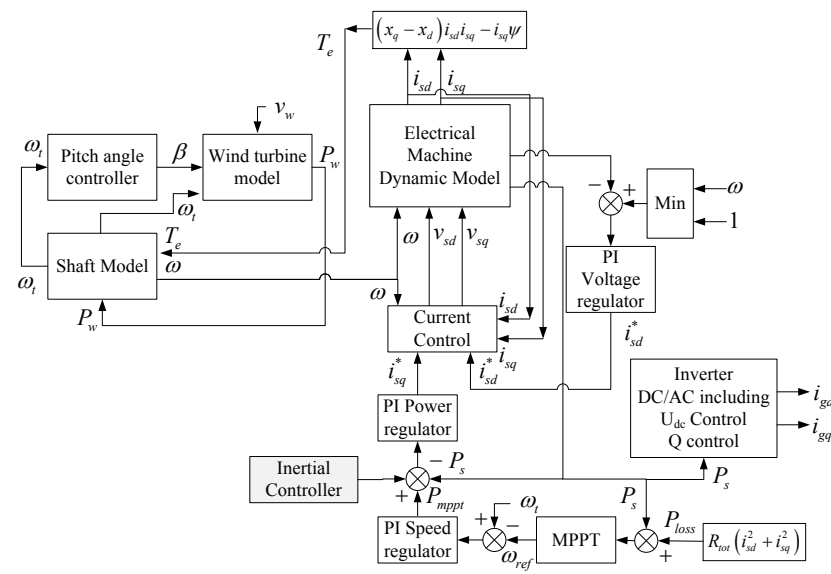

Figure 5. Representative block diagram of main elements, controller and signals using on the model of VSWT with a DD synchronous generator with a FRPC.

Figure 5 shows block diagram of the main components and controller considering on the modelling of VSWT with a DD synchronous generator with a FRPC as interface to grid. A time series can be used as input of wind turbine rotor model, for simplicity in this paper constant speed is assumed during the simulation time. The variable speed wind turbine rotor model consists of the classical polynomic relationship between wind speed and mechanical power. The model for the mechanical shaft consists of a simple a classical two mass representation. Maximum power point tracking controller is included in order to provide the speed control of the wind turbine and it is aimed to maximize its power production. Pitch angle controller is included in the model aiming to reduce of the power extracted from the wind at very high wind speed. As far as the generator side converter is concerned, two main control loops are present, namely: the active power/speed control loop and the voltage control loop. Such loops will provide the reference signals for the two inner current control loops. The grid side converter is composed of basically two outer control loops, regulating the voltage $\left(U_{d c}\right)$ on the DC link and the reactive power $\left(Q_{n e t}\right)$ delivered to the network. Again, such loops will provide the reference signals for the two inner current control loops. Details of control modelling are beyond the scope of this paper, however, further details can be found on [28], [29].

\section{SIMULATION AND RESULTS}

This section presents a comparison of two inertial controller enabling frequency control in wind turbines: (A) releasing "hidden" inertia controller and (B) fast power reserve emulation. Simulations and results over a simple Test System, shown in Figure 3, are presented in this section. An equivalent synchronous generator (GS) and load are used as representative equivalent model of a traditional power system and a small transmission system is included considering two voltage levels. System model and wind turbine controllers (as described in section II and III) are implemented using Matlab/Simulink. In this paper, system disturbance consist of generated outage simulated by a sudden increase on active power demand. The system disturbance is inserted at $t_{0}=$ $10.0 \mathrm{~s}$.

\section{A. System Frequency Response}

Time domain response of the main frequency response are plotted in Figure 6 . When the frequency limit $\left(f_{\text {activation }}\right)$ is exceeded, the frequency-support controller is activated providing inertial response, resulting in sudden increase on active power injection to the equivalent network and providing support on transiently re-establishing the power-balance and helping on frequency support. The wind turbine output power delivered to the grid increases when the system frequency exceeds its limit and the controller is activated $\left(f_{\text {activation }}=49.9\right.$ $\mathrm{Hz}$ ). Controller (A) will shut down when frequency reaches a new steady state while controller $(B)$ turns off after 5 seconds. The wind turbine has an initial active power production below rated power ( 0.55 p.u). During the inertial response, it is seen a sudden increase of the inertial power contribution provided by the WT equipped with hidden inertial controller $\left(P_{\text {inertial,max }}=\right.$ 0.596 p.u), however, the fast power reserve emulation controller allows reaching a larger power contribution in a longer period $\left(P_{\text {inertial,max }}=0.645\right.$ p.u @ 5.33sec $)$-see Table I for more details. The quantity of power taken from kinetic energy $-H w^{2}$, depends on the inertial controllers enabled on the wind turbine. The higher is the inertial power contribution, the higher is the decrease of kinetic energy during the frequency disturbance, and most important, the energy recovery after disturbance will require a longer time. Because kinetic energy from the wind turbine is used to supply more power to the grid, the rotational speed of the turbine and wind power are decreasing. After the inertial response wind turbine resumes normal operation at different time, depending on the inertial controller used: longer time is required by the fast power reserve emulation controller.

The output power drops to a value that is lower than the initial one, because the turbine is not at its optimal speed 
anymore. Then, power is needed to speed the turbine up to its optimal speed, which implies that only a part of the available aerodynamic power is transmitted to the grid. The drop in power also explains why the frequency curves are different from each other after.


Figure 6. Plots of the main variable of SFR during a sudden demand increase: Time domain plots.

TABLE I. COMPARISON OF MAIN INDICATORS OF SFR BETWEEN INERTIAL CONTROLLERS

\begin{tabular}{|l|c|c|}
\hline \multicolumn{1}{|c|}{ Indicator } & $\begin{array}{c}\text { Hidden inertia } \\
\text { controller }\end{array}$ & $\begin{array}{c}\text { Fast power } \\
\text { reserve emulation }\end{array}$ \\
\hline Min. Frequency, $f_{\min }[\mathrm{p} . \mathrm{u}]$ & 0.975 & 0.975 \\
\hline Max. Kinetic Energy Contribution [s] & 0.096 & 0.211 \\
\hline Max. Power, $P_{\max }[\mathrm{p} . \mathrm{u}]$ & 0.5943 & 0.6512 \\
\hline Time @ $P_{\max }[\mathrm{sec}]$ & 0.09 & 5.27 \\
\hline
\end{tabular}

\section{B. Sensitivity analysis of synthetic inertia controllers}

This subsection presents a sensitivity analysis of frequency responses of each controller considering changes on their main parameters. Case $I$ : Initially the value of the gain $\left(H_{s y n}=3.5\right.$, $7.01,14.02$ and $28.04 \mathrm{~s}$ ) in the synthetic inertia controller is changed to assess the frequency response as shown on Figure 7. Case II: parameter of the fast power reserve emulation are changed considering, $\left(P_{\text {syn }} / H_{\text {syn }}\right) t=0.125,0.25,0.5$ and 0.75 (see Figure 8).

It is clear that increasing the gain in both controller the inertial power contribution is increased during the system frequency response, however, it must be noticed two important aspects: (i) hidden inertia controller allow a very fast active power contribution with a high $d P / d t$ and (ii) fast power reserve emulation controller provide a smoother response (lower $d P / d t)$, but depending on the slope included in the controller $\left(P_{\text {syn }} / H_{\text {syn }}\right) t$, the inertial power contribution could reach rated power (1.0 p.u as depicted on Figure 8). However, the main issue with the fast power reserve emulation controller is the deactivation time (here set to $5 \mathrm{~s}$ ), which interrupts the inertial power contribution and potentially initiate a second system frequency disturbance.
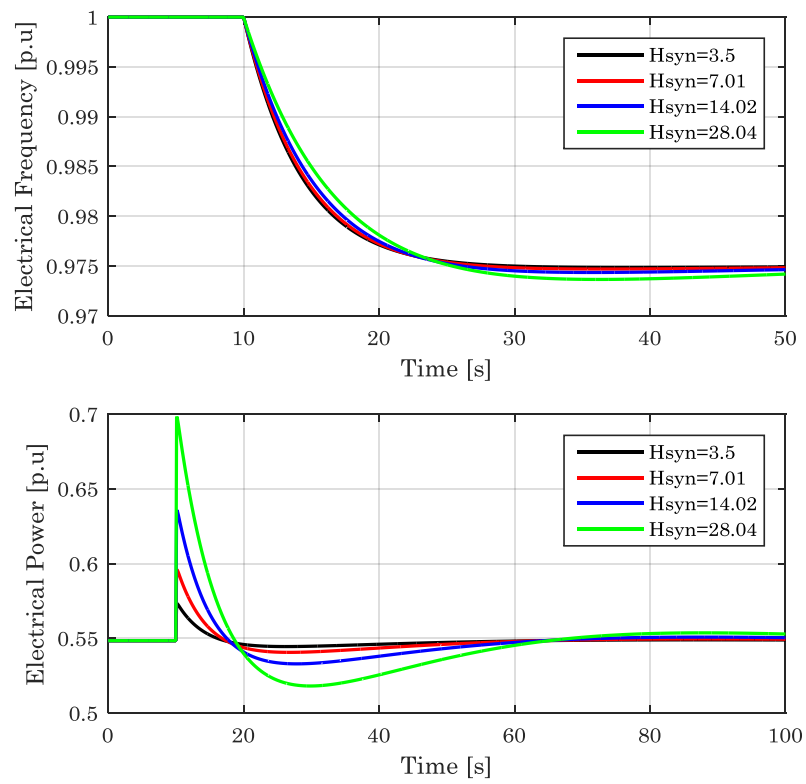

Figure 7. Plot of the main variable of SFR during a sudden demand increase: Case I: Hidden inertia controller.
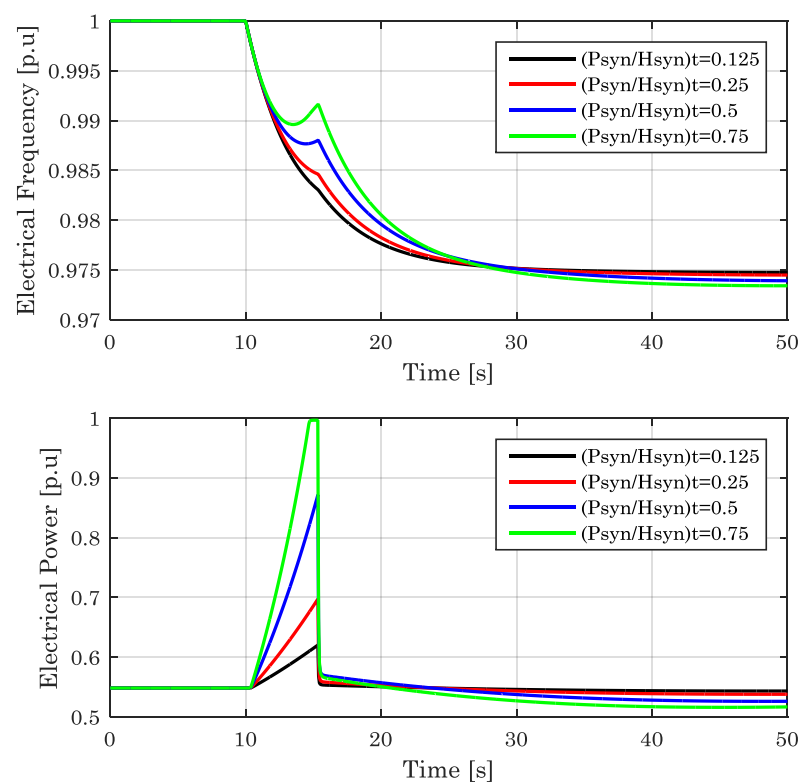

Figure 8. Plot of the main variable of SFR during a sudden demand increase: Case II: Fast power reserve emulation. 


\section{CONCLUSION}

This paper evaluated two inertial controller for full-rated power converter wind turbines, Type 4: (A) releasing "hidden" inertia controller and (B) fast power reserve emulation. Simulations over a test system are used for a preliminary evaluation of the mentioned inertial controllers. Time domain simulations and results demonstrate the difference on the system frequency response between those controllers.

The main contribution of this paper is to demonstrate the main differences between system SRF obtained by each inertial controller: (i) hidden inertia controller allow a very fast active power contribution with a high $\mathrm{dP} / \mathrm{dt}$; this characteristic is specially desirable in low inertia systems (ii) fast power reserve emulation controller provide a smooth response (lower $d P / d t$ ), but depending on the slope included in the controller $\left(P_{\text {syn }} / H_{\text {syn }}\right) t$, the inertial power contribution could reach the WTG rated power. The performance of this controller can be especially desirable in high inertia system, where the controller will provide inertia power avoiding the action of under frequency protection schemes and allowing time to high inertia generators to actuate. However, the main issue with the fast power reserve emulation controller is the deactivation time, which potentially initiate a second system frequency disturbance.

\section{REFERENCES}

[1] F. Gonzalez-Longatt, "Frequency Control and Inertial Response Schemes for the Future Power Networks," in Large Scale Renewable Power Generation, J. Hossain and A. Mahmud, Eds., ed: Springer Singapore, 2014, pp. 193-231.

[2] F. M. Gonzalez-Longatt, "Activation schemes of synthetic inertia controller on full converter wind turbine (type 4)," in Power \& Energy Society General Meeting, 2015 IEEE, 2015, pp. 1-5.

[3] F. M. Gonzalez-Longatt, "Effects of the synthetic inertia from wind power on the total system inertia: simulation study," in Environment Friendly Energies and Applications (EFEA), 2012 2nd International Symposium on, 2012, pp. 389-395

[4] F. Gonzalez-Longatt, "Impact of synthetic inertia from wind power on the protection/control schemes of future power systems: Simulation study," in Developments in Power Systems Protection, 2012. DPSP 2012. 11th International Conference on, 2012, pp. 1-6.

[5] A. Bonfiglio, M. Brignone, F. Delfino, M. Invernizzi, F. Pampararo, and R. Procopio, "A technique for the optimal control and operation of gridconnected photovoltaic production units," in Universities Power Engineering Conference (UPEC), 2012 47th International, 2012, pp. 16.

[6] A. Bonfiglio, M. Brignone, F. Delfino, and R. Procopio, "Optimal Control and Operation of Grid-Connected Photovoltaic Production Units for Voltage Support in Medium-Voltage Networks," Sustainable Energy, IEEE Transactions on, vol. 5, pp. 254-263, 2014.

[7] A. Bonfiglio, F. Delfino, M. Invernizzi, R. Procopio, and P. Serra, "Criteria for the equivalent modeling of large photovoltaic power plants," in PES General Meeting | Conference \& Exposition, 2014 IEEE, 2014, pp. $1-5$

[8] F. Gonzalez-Longatt, "Frequency Control and Inertial Response Schemes for the Future Power Networks," in Advances in Technologies for Generation, Transmission and Storage, Green Energy and Technology Series. vol. VIII, J. Hossain and A. Mahmud, Eds., ed Singapur: Springer-Verlag, 2014, p. 363.

[9] J. B. Ekamayake, N. Jenkins, and G. Strbac, "Frequency Response From Wind Turbines," Wind Engineering, vol. 32, pp. 537-586, 2008
[10] N. Plc. (2010). National Grid, Grid Code Frequency Response Working Group: "Simulated Inertia". http://www.nationalgrid.com/uk/Electricity/Codes/gridcode/workinggrou $\mathrm{ps} /$ freqresp/

[11] GE. (2009). WindINERTIA Control fact sheet. Available: http://www.geenergy.com/products and services/products/wind turbines/index.jsp

[12] J. Morren, S. W. H. de Haan, W. L. Kling, and J. A. Ferreira, "Wind turbines emulating inertia and supporting primary frequency control," Power Systems, IEEE Transactions on, vol. 21, pp. 433-434, 2006.

[13] I. Erlich and M. Wilch, "Primary frequency control by wind turbines," in Power and Energy Society General Meeting, 2010 IEEE, 2010, pp. 1-8.

[14] S. Yuan-zhang, Z. Zhao-sui, L. Guo-jie, and L. Jin, "Review on frequency control of power systems with wind power penetration," in Power System Technology (POWERCON), 2010 International Conference on, 2010, pp. 1-8.

[15] J. Ekanayake and N. Jenkins, "Comparison of the response of doubly fed and fixed-speed induction generator wind turbines to changes in network frequency," Energy Conversion, IEEE Transactions on, vol. 19, pp. 800802,2004

[16] R. Doherty, A. Mullane, G. Nolan, D. J. Burke, A. Bryson, and M. O'Malley, "An Assessment of the Impact of Wind Generation on System Frequency Control," Power Systems, IEEE Transactions on, vol. 25, pp. 452-460, 2010.

[17] I. Erlich, W. Winter, and A. Dittrich, "Advanced grid requirements for the integration of wind turbines into the German transmission system," in Power Engineering Society General Meeting, 2006. IEEE, 2006, p. 7 pp.

[18] D. Gautam, L. Goel, R. Ayyanar, V. Vittal, and T. Harbour, "Control Strategy to Mitigate the Impact of Reduced Inertia Due to Doubly Fed Induction Generators on Large Power Systems," Power Systems, IEEE Transactions on, vol. 26, pp. 214-224, 2011

[19] F. M. Gonzalez-Longatt, "Impact of emulated inertia from wind power on under-frequency protection schemes of future power systems," Journal of Modern Power Systems and Clean Energy, pp. 1-8, 2015/08/12 2015.

[20] G. Lalor, A. Mullane, and M. O'Malley, "Frequency control and wind turbine technologies," Power Systems, IEEE Transactions on, vol. 20, pp. 1905-1913, 2005.

[21] F. M. Gonzalez-Longatt, "Activation schemes of synthetic inertia controller for full converter wind turbine generators," in PowerTech, 2015 IEEE Eindhoven, 2015, pp. 1-5

[22] N. Miller, K. Clark, and R. Walling, "WindINERTIA: Controlled Inertial Response from GE Wind Turbine Generators," presented at the 45th Annual Minnesota Power Systems Conference, Minneapolis, Minnesota, 2009

[23] S. Wachtel and A. Beekmann, "Contribution of Wind Energy Converters with Inertia Emulation to Frequency Control and Frequency Stability in Power Systems," presented at the 8th International Workshop on LargeScale Integration of Wind Power into Power Systems as well as on Transmission Networks for Offshore Wind Farms, Bremen, Germany, 2009

[24] F. Gonzalez-Longatt, "Impact of synthetic inertia from wind power on the protection/control schemes of future power systems: Simulation study," in 11th International Conference on Developments in Power Systems Protection, 2012. DPSP 2012. , 2012, pp. 1-6.

[25] K. Ping-Kwan, L. Pei, H. Banakar, and B. T. Ooi, "Kinetic Energy of Wind-Turbine Generators for System Frequency Support," Power Systems, IEEE Transactions on, vol. 24, pp. 279-287, 2009.

[26] A. Teninge, C. Jecu, D. Roye, S. Bacha, J. Duval, and R. Belhomme, "Contribution to frequency control through wind turbine inertial energy storage," Renewable Power Generation, IET, vol. 3, pp. 358-370, 2009.

[27] N. R. Ullah, T. Thiringer, and D. Karlsson, "Temporary Primary Frequency Control Support by Variable Speed Wind Turbines\&\#x2014; Potential and Applications," Power Systems, IEEE Transactions on, vol. 23, pp. 601-612, 2008.

[28] O. Anaya-Lara, Wind energy generation : modelling and control. Oxford: Wiley, 2009.

[29] T. Ackermann, Wind power in power systems. Chichester: John Wiley \& Sons, 2005 